\title{
Extrapleural hematoma cases treated with video-assisted thoracoscopic surgery
}

\author{
Mehmet Gökhan Pirzirenli, M.D., Burçin Çelik, M.D., Selçuk Gürz, M.D., Zeynep Pelin Sürücü, M.D.
}

Department of Thoracic Surgery, Ondokuz Mayis University Faculty of Medicine, Samsun

\begin{abstract}
Extrapleural hematoma is a rare clinical condition whose most common causes are blunt chest trauma, central venous catheterization and ruptured thoracic aortic aneurysm. This study aimed to present three cases that underwent video-assisted thoracoscopic surgery due to extrapleural hematoma. Etiologic factors in these cases were falls from height in two cases and a dialysis catheter placed into the right internal jugular vein in one case.
\end{abstract}

Keywords: Extrapleural; hematoma; treatment; video-assisted thoracoscopic surgery.

\section{INTRODUCTION}

Extrapleural hematoma $(\mathrm{EPH})$ is a rare clinical condition since the expansion of extrapleural space and accumulation of blood in this region is quite difficult. EPH is classified into three groups including spontaneous, iatrogenic and traumatic. ${ }^{[l]}$ Blunt chest trauma, central venous catheterization and ruptured thoracic aortic aneurysm are the most frequent etiological factors. Rashid et al. have reported that the incidence of $\mathrm{EPH}$ in thoracic trauma is $7.1 \%$, and the mortality rate in the early period is $2.9 \%$. $^{[l]}$ Diagnostic evidence in thoracic computed tomography are the observation of extrapleural fat sign, namely, separation of parietal pleura from endothoracic fascia and medial translocation, and fluid accumulation in the area. ${ }^{[2,3]}$

In this article, three patients diagnosed with extrapleural hematoma and treated with VATS (video-assisted thoracoscopic surgery) were presented by reviewing the literature.

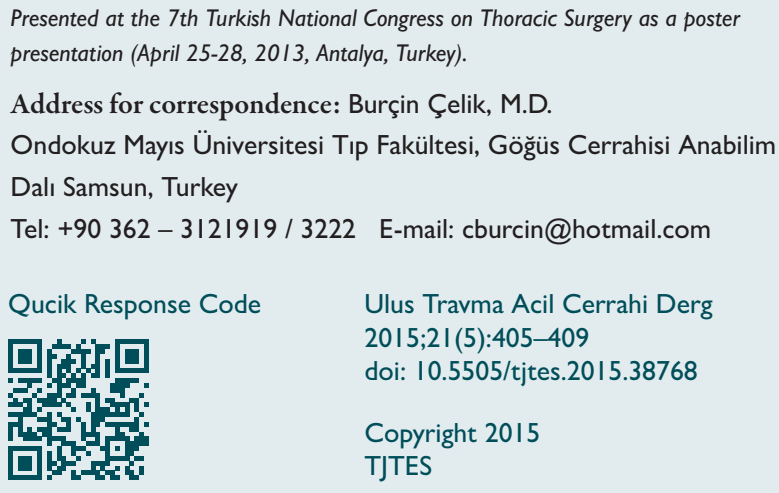

\section{Anesthesia Management}

Electrocardiogram, heart rate and blood pressure were monitored in all patients. Venous cannula was inserted into a peripheral vein and a radial arterial cannula was inserted under local anesthesia. Additional monitoring included $\mathrm{SpO}_{2}$, urine output and peak airway pressure. After inhaling $100 \%$ oxygen for 5 minutes, anesthesia was induced with $0.2 \mu \mathrm{g} / \mathrm{kg} /$ min dose of remifentanil (Ultiva, Glaxo Smith Kline, UK) and 2-3 mg/kg dose of propofol (Diprivan, Astra Zeneca, UK). Neuromuscular blockage was achieved with $0.2 \mathrm{mg} / \mathrm{kg}$ dose of cisatracurium (Nimbex, Glaxo Smith Kline, UK), followed by endobronchial intubation with a left-sided double-lumen tube (Portex, U.S.A). Correct positioning of the endobronchial tube was confirmed by auscultation before and after the patient was positioned in the lateral decubitus position. Ventilation was controlled with a 50:50 mixture of oxygen and air. Tidal volume was designed to be as; respiration frequency $10-12 / \mathrm{min}$ and end-tidal carbon dioxide pressure $30-35 \mathrm{~mm}$ $\mathrm{Hg}$. During one lung ventilation, the lumen of the tube remained open to the air.

\section{Surgical Procedure}

In the lateral decubitus position, at the seventh intercostal space in the midaxillary line, a thoracoport was placed and the thorax was entered with a video camera at an angle of 30 degrees. The diagnosis of extrapleural hematoma was confirmed with this procedure. Two thoracoports were placed at the fifth intercostal spaces in the anterior and posterior axillary lines. The parietal pleura detached from the chest wall due to extrapleural hematoma were opened and the hematoma was drained. Partial pleurectomy was performed to the parietal pleura, and the detected hemorrhagic 

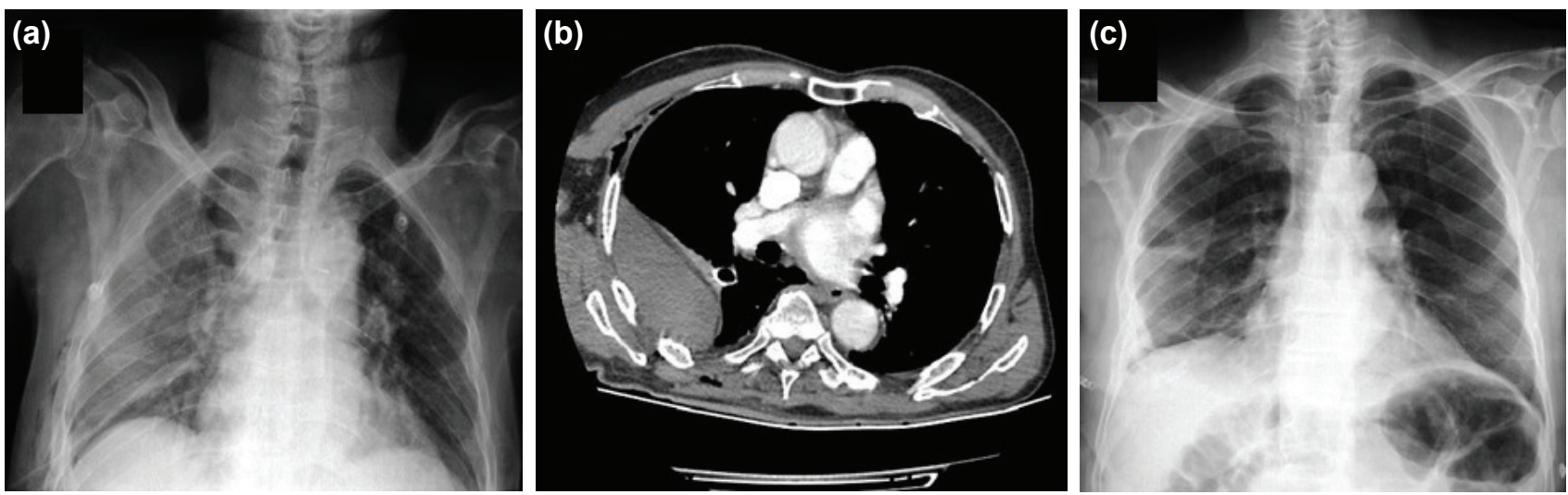

Figure 1. (a) Extrapleural hematoma in the right hemithorax is seen in the postero-anterior chest radiography and (b) CT scan of the first patient who fell from height. (c) Drained EPH is seen in the postoperative chest radiograph.

focus was closed with endoclip. Thoracic cavity was washed, and the procedure was ended by placing a size 32 thoracic catheter.

Case I- Two days prior, the 83-year-old male patient had been admitted to another clinical center with the complaint of a fall from height and had been diagnosed with hemothorax after radiological evaluation. The patient who had undergone right tube thoracostomy was referred to our clinic since no improvement in the hemothorax had been observed in direct radiography. The patient complained shortness of breath, and his physical examination revealed decreased breath sounds in the right hemithorax. Abdominal ultrasonography revealed free fluid in and around the spleen. Blood pressure and pulse rate were normal. Initial laboratory results were as follows: hemoglobin $9.4 \mathrm{~g} / \mathrm{dl}$, hematocrit $30.1 \%$, pH 7.46, $\mathrm{pO}_{2} 77.8$ $\mathrm{mmHg}, \mathrm{PCO}_{2} 32.6 \mathrm{mmHg}, \mathrm{SpO}_{2}$ 96\%, PT II.6 sec, PTT 21.9 sec, INR I.05. He was an ex-smoker.

Since it was detected in the chest X-ray that hemothorax persisted despite the tube thoracostomy, thoracic CT was performed. Thoracic CT revealed extrapleural hematoma in the right hemithorax, but no rib or sternum fracture was observed (Fig. I). CT-guided catheter was inserted by the interventional radiology to drain the $\mathrm{EPH}$, but adequate drainage could not be achieved. No radiological improvement was achieved, and the patient's shortness of breath persisted, so VATS was planned. During exploration, extrapleural hematoma was detected on the lateral wall of the thorax (Fig. 2). A hematoma of approximately $800 \mathrm{~mL}$ was drained and partial pleurectomy was performed by means of VATS. No active bleeding source was detected. The patient did not have any problems during follow up and was discharged on the sixth postoperative day.

Case 2- The 66-year-old male patient presented to the Emergency Department stated that he had fallen from a I-meter height. His complaints were chest pain and shortness of breath. During physical examination, decreased breath sound was detected in the left lower and middle zones by listening. Chest X-ray revealed hemothorax on the left hemithorax (Fig. 3a). A fracture on the seventh vertebral corpus and an extrapleural hematoma about $10 \mathrm{~cm}$ in diameter were observed in thoracic CT. There was no rib fracture (Fig. 3b). Tube thoracostomy failed to provide adequate drainage, so VATS was planned. The initial laboratory results were as follows; hemoglobin $10.5 \mathrm{~g} / \mathrm{dl}$, hematocrit $30.3 \%, \mathrm{pH} 7.39, \mathrm{pO}_{2}$ $77.9 \mathrm{mmHg}, \mathrm{PCO}_{2} 35.6 \mathrm{mmHg}, \mathrm{SpO}_{2} 95 \%$, PT $13.3 \mathrm{sec}$, PTT $25.2 \mathrm{sec}$, INR I.2I. He was an ex-smoker.

On exploration, extrapleural hematoma was detected in the paravertebral area from the apex down to the diaphragm. There was bleeding at the left seventh intercostal artery which was ligated with endoclip, and partial pleurectomy was performed via VATS. The amount of hematoma drained was approximately $1000 \mathrm{~mL}$. The patient was discharged with recommendations on the sixth postoperative day (Fig. 3c).

Case 3- The 36-year-old male patient diagnosed with chronic renal failure had undergone dialysis catheter insertion into

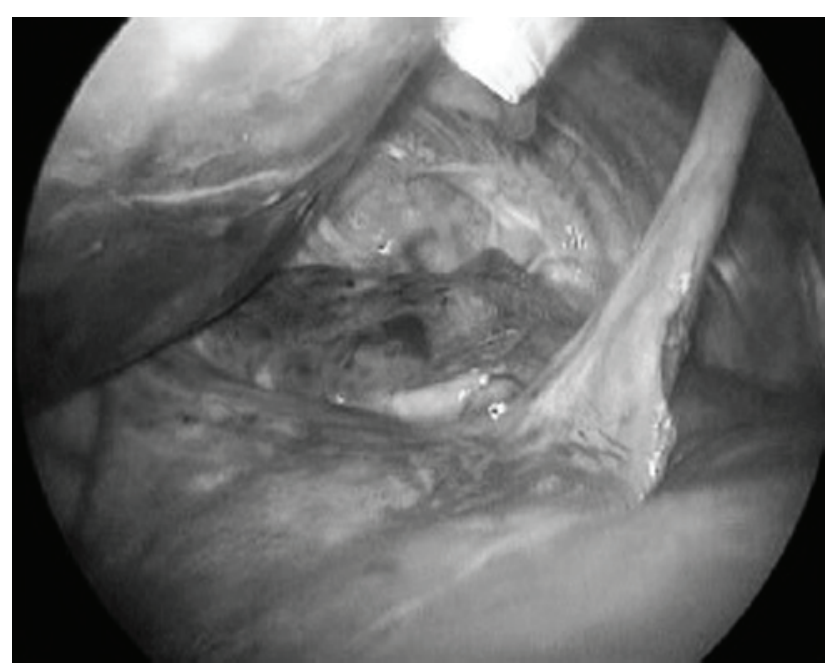

Figure 2. During exploration, extrapleural hematoma was detected on the lateral wall of the right hemithorax. 

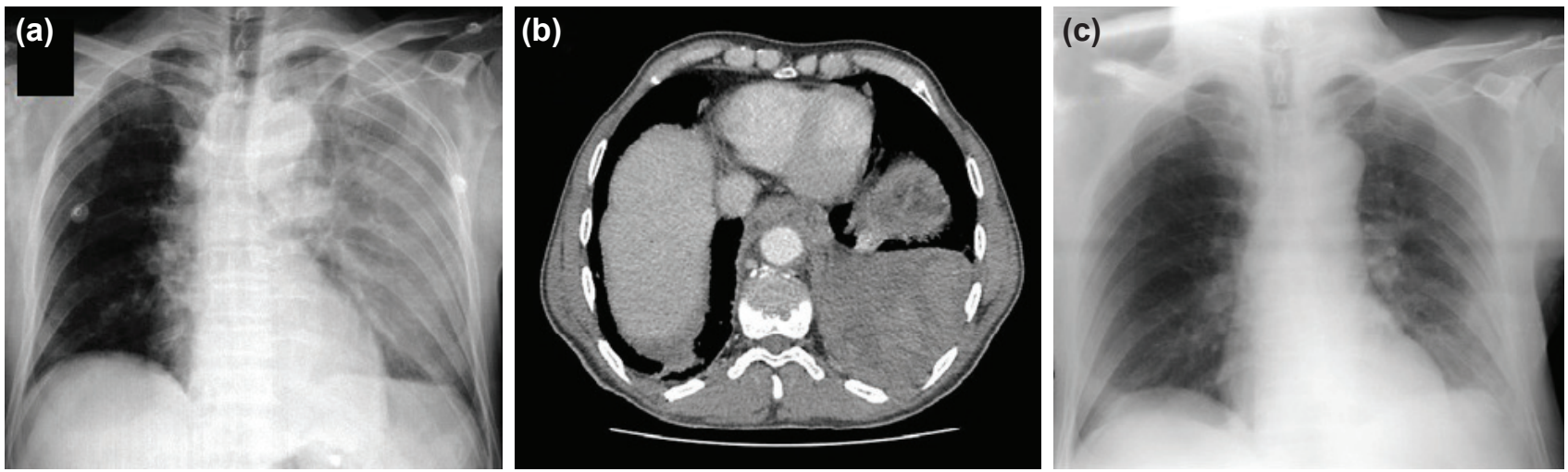

Figure 3. (a) Hematoma in the left hemithorax is seen in the postero-anterior chest radiography of the second patient who fell from height. (b) Fracture in the 7 th thoracic vertebra and approximately $10-\mathrm{cm}$ extrapleural hematoma in the left hemithorax is seen in thoracic CT. (c) No pathology is observed in the postero-anterior chest radiography after draining the hematoma.

the right jugular vein 10 days before he was referred to our clinic. Following the procedure, he had developed shortness of breath and chest pain. Chest X-ray had been performed, and right hemothorax had been observed. Consequently, a chest tube had been placed. Following the failure to provide adequate drainage, the patient had been referred to our clinic. His thorax CT revealed an 8-cm-diameter extrapleural hematoma in the right hemithorax (Fig. 4). Initial laboratory results were as follows; hemoglobin $7.20 \mathrm{~g} / \mathrm{dl}$, hematocrit $22.3 \%, \mathrm{pH}$ 7.37, $\mathrm{pO}_{2} 56.0 \mathrm{mmHg}, \mathrm{pCO}_{2} 36.0 \mathrm{mmHg}, \mathrm{SpO}_{2}$ 91\%, PT I2.6 $\mathrm{sec}$, PTT $26.0 \mathrm{sec}$, INR I.2I. His hemoglobin value decreased from 7.20 to $6.30 \mathrm{~g} / \mathrm{dl}$, and accordingly VATS was planned. He was a non-smoker.

Extrapleural hematoma and dialysis catheter-induced mediastinal hematoma adjacent to the vena cava superior were determined on exploration, but no active source of bleeding was detected. An approximately $400 \mathrm{~mL}$ of extrapleural hematoma was totally drained, and partial pleurectomy was performed. While the drainage was going on through the postoperative chest tube, the catheter in the internal jugular vein was replaced with a new dialysis catheter. Since the hemorrhage occurred after dialysis, dialysis was performed without heparin administration. After the renewal of the catheter, hemorrhagic drainage ceased and his chest tube was removed. The patient underwent medical treatment due to pneumonic infiltration developed in the right lower lobe and was discharged with recovery on the fifteenth postoperative day.

\section{DISCUSSION}

Traumatic EPH was first described by Lipchik and Robinson in 1968. ${ }^{[4]}$ Extrapleural hematoma, defined as the accumulation of blood in the extrapleural space, is one of the rare complications of blunt chest trauma. Among the other causes are penetrating thoracic trauma, aortic rupture and iatrogenic procedures. In thoracic trauma, parietal pleura are often injured generally leading to hemothorax. On the other hand, in $\mathrm{EPH}$, parietal pleura remain intact and the bleeding canalizes into the extrapleural space. The source of bleeding in EPH is usually intercostal or internal mammarian veins. ${ }^{[5]}$ Minor injuries in mediastinal structures, traumatic aortic rupture and vertebral and rib fractures are the other bleeding sources. [I] Among the differential diagnosis are encysted pleural effusion, pleural tumors, peripheral lung tumors, oleothorax, round atelectasis and diaphragmatic hernias. ${ }^{[1,6]}$
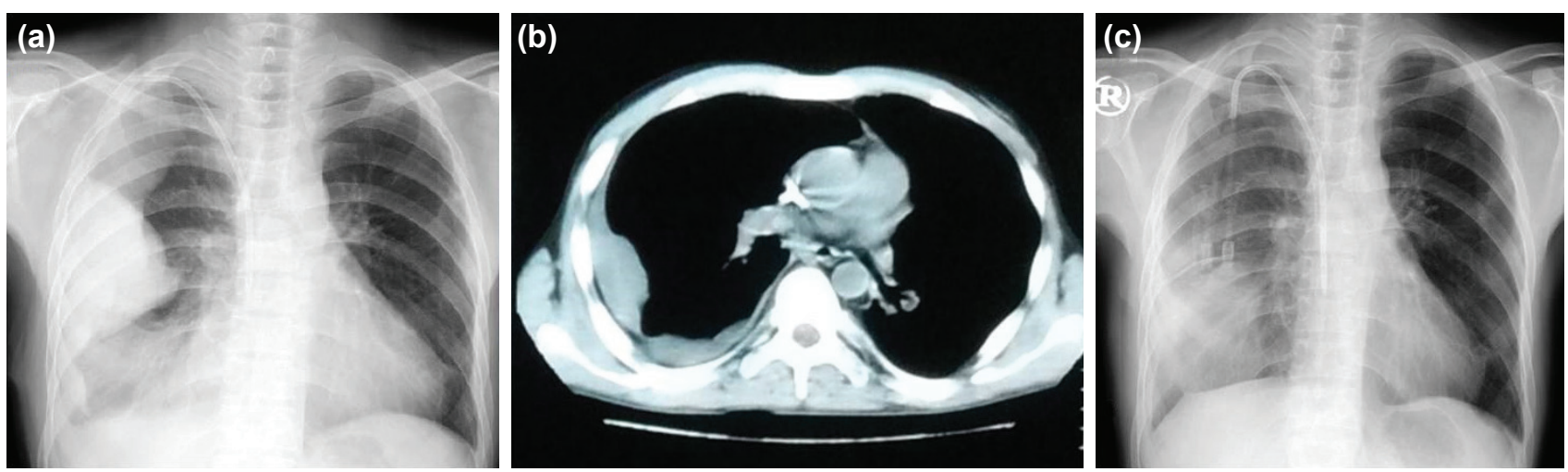

Figure 4. (a,b) The extrapleural hematoma which developed after the placement of a dialysis catheter into the internal jugular vein is seen in direct chest radiography and thoracic CT. (c) After the draining the hematoma, no pathology is seen in the chest radiography, except an infiltration in the right lower lobe. 
Since extrapleural hematoma leads to respiratory and circulatory problems, correct and definitive diagnosis should be timely. ${ }^{[7]}$ Clinical manifestations of EPH are bleeding, chest pain and shortness of breath. While chest pain is the most commonly encountered symptom, most of the cases are asymptomatic. In cases of hemothorax, if enough drainage and radiological improvement cannot be achieved with the insertion of chest tube, EPH is suspected, and further radiological imaging and evaluation is performed. When the posteroanterior and lateral chest radiographies reveal a D-shaped opacity on the chest wall, thoracic CT is performed, and the detection of the progression of the extrapleural fat tissue into the thorax and the dislocation of the parietal pleura (extrapleural fat sign) confirm the diagnosis. ${ }^{[1-3]}$

Chung et al. ${ }^{[7]}$ have classified EPH in two groups; biconvex and nonconvex. They have defined that biconvex EPHs have larger diameters and possibly develop due to arterial injury, while nonconvex EPHs have smaller diameters and develop due to bleedings with lower pressure. In nonconvex EPH, bleeding often originates from venous structures and pericostal hematomas. In EPH, size and shape are guides for surgical treatment. Biconvex EPHs with large volume require surgical treatment. ${ }^{[7]}$

Whether surgical treatment is required or not depends on the patient's clinical status. The most serious life-threatening complication is massive bleeding originating from great vessels. Patients with a small EPH and stable patients do not require any interference, and hematoma may resolve spontaneously. ${ }^{[8]}$ However, massive EPH, which causes severe respiratory and circulatory symptoms, requires invasive procedures. In two of our cases, the size of EPH was quite large and was causing shortness of breath. In the third case, although the size of EPH was not large, the patient was symptomatic. Treatment methods are tube thoracostomy, VATS and thoracotomy. CT guided pleural catheter placement at the site of hematoma and delivery of thrombolytic therapy is another method, but we do not believe that the delivery of thrombolytic therapy without determining the underlying cause is a right method. Furthermore, neither pleural catheter nor tube thoracostomy will be successful since there is a clotted hemothorax in EPH. As reported in many publications, VATS is the right and precise treatment method in evacuating the clotted hemothorax and in controlling the bleeding center.

It has been stated that VATS is not the appropriate approach for such cases, because extrapleural area cannot be imaged clearly due to the absence of anatomical cavity. ${ }^{[1]}$ On the other hand, some studies have stated that VATS is the appropriate method to explore the extrapleural area, evacuate the hematoma by opening the parietal pleura and determine the bleeding center. ${ }^{[5,6]}$ We also think that in cases where tube thoracostomy fails to provide adequate drainage and EPH is suspected, VATS should be the first preference. If VATS does not yield good results, then hematoma should be drained with thoracotomy.

Extrapleural hematoma develops spontaneously, or due to traumatic or iatrogenic factors. Since parietal pleura are still intact, bleeding canalizes into the extrapleural space, and parietal pleura is separated from endothoracic fascia due to the pressure caused by bleeding. When radiological imaging reveals persistent opacity after the performance of tube thoracostomy with the diagnosis of hemothorax, extrapleural hematoma should be suspected, and VATS should be considered as a highly reliable method.

\section{Acknowledgements}

We also thank Salih Yılmaz for editing the language in an earlier version of this manuscript.

Conflict of interest: None declared.

\section{REFERENCES}

1. Rashid MA, Wikström T, Ortenwall P. Nomenclature, classification, and signficance of traumatic extrapleural hematoma. J Trauma 2000;49:28690. CrossRef

2. Aquino SL, Chiles C, Oaks T. Displaced extrapleural fat as revealed by CT scanning: evidence of extrapleural hematoma. AJR Am J Roentgenol 1997;169:687-9. CrossRef

3. Hammerman AM, Susman N, Strzembosz A, Kaiser LR. The extrapleural fat sign: CT characteristics. J Comput Assist Tomogr 1990;14:345-7.

4. Lipchik EO, Robinson KE. Acute traumatic rupture of the thoracic aorta. Am J Roentgenol Radium Ther Nucl Med 1968;104:408-12. CrossRef

5. Goh BK, Koong HN. Massive traumatic extrapleural hematoma mimicking hemothorax: a potential pitfall of penetrating chest trauma. J Trauma 2006;61:995-7. CrossRef

6. Poyraz AS, Kilic D, Gultekin B, Ozulku M, Hatipoglu A. Extrapleural hematoma: when is surgery indicated? Monaldi Arch Chest Dis 2005;63:166-9.

7. Chung JH, Carr RB, Stern EJ. Extrapleural hematomas: imaging appearance, classification, and clinical significance. J Thorac Imaging 2011;26:218-23. CrossRef

8. Noguchi T, Hida Y, Kaga K, Kawada M, Niizeki H, Kondo S. Extrapleural hematoma as a complication following thoracotomy for pulmonary lobectomy. Gen Thorac Cardiovasc Surg 2011;59:57-60. CrossRef 


\section{OLGU SUNUMU - ÖZET}

\section{Video-yardımlı torakoskopik cerrahi ile tedavi edilen ekstraplevral hematomlu olgular} Dr. Mehmet Gökhan Pirzirenli, Dr. Burçin Çelik, Dr. Selçuk Gürz, Dr. Zeynep Pelin Sürücü

Ondokuz Mayıs Üniversitesi Tıp Fakültesi, Göğüs Cerrahisi Anabilim Dalı, Samsun

Ekstraplevral hematom oldukça nadir bir klinik durumdur ve etiyolojisinde en sık künt toraks travması, santral venöz kateterizasyon ve torasik aort anevrizması rüptürü bulunmaktadır. Burada ekstraplevral hematom nedeniyle video-yardımlı torakoskopik cerrahi ile tedavi ettiğimiz üç olguyu sunduk. Bu olgularda etiyolojik faktörler; iki olguda yüksekten düşme ve bir olguda sağ internal juguler vene yerleştirilen diyaliz kateteri idi.

Anahtar sözcükler: Ekstraplevral; hematom; tedavi; video-yardımlı torakoskopik cerrahi

Ulus Travma Acil Cerrahi Derg 20I5;2I(5):405-409 doi: I0.5505/tjtes.20I5.38768 